\title{
Happy eating : the underestimated role of overeating in a positive mood
}

Citation for published version (APA):

Bongers, P., Jansen, A., Havermans, R., Roefs, A., \& Nederkoorn, C. (2013). Happy eating : the underestimated role of overeating in a positive mood. Appetite, 67(1), 74-80.

https://doi.org/10.1016/j.appet.2013.03.017

Document status and date:

Published: 01/01/2013

DOI:

10.1016/j.appet.2013.03.017

Document Version:

Publisher's PDF, also known as Version of record

Document license:

Taverne

Please check the document version of this publication:

- A submitted manuscript is the version of the article upon submission and before peer-review. There can be important differences between the submitted version and the official published version of record.

People interested in the research are advised to contact the author for the final version of the publication, or visit the DOI to the publisher's website.

- The final author version and the galley proof are versions of the publication after peer review.

- The final published version features the final layout of the paper including the volume, issue and page numbers.

Link to publication

\footnotetext{
General rights rights.

- You may freely distribute the URL identifying the publication in the public portal. please follow below link for the End User Agreement:

www.umlib.nl/taverne-license

Take down policy

If you believe that this document breaches copyright please contact us at:

repository@maastrichtuniversity.nl

providing details and we will investigate your claim.
}

Copyright and moral rights for the publications made accessible in the public portal are retained by the authors and/or other copyright owners and it is a condition of accessing publications that users recognise and abide by the legal requirements associated with these

- Users may download and print one copy of any publication from the public portal for the purpose of private study or research.

- You may not further distribute the material or use it for any profit-making activity or commercial gain

If the publication is distributed under the terms of Article $25 \mathrm{fa}$ of the Dutch Copyright Act, indicated by the "Taverne" license above, 
Research report

\title{
Happy eating. The underestimated role of overeating in a positive mood ${ }^{\text {मे }}$
}

\author{
Peggy Bongers*, Anita Jansen, Remco Havermans, Anne Roefs, Chantal Nederkoorn \\ Faculty of Psychology and Neuroscience, Maastricht University, CPS, Department of Eating Disorders and Addiction, P.0. Box 616, 6200 MD Maastricht, The Netherlands
}

\section{A R T I C L E I N F O}

\section{Article history:}

Received 17 September 2012

Received in revised form 14 March 2013

Accepted 21 March 2013

Available online 10 April 2013

\section{Keywords:}

Emotional eating

Mood induction

Positive emotions

Food consumption

Mood repair

\begin{abstract}
A B S T R A C T
Emotional eaters are often presumed to eat in response to negative emotions, while positive emotions have been largely neglected. The current study induced a positive, negative, or neutral mood in a student sample and subsequently measured food intake. In addition, the relation between caloric intake and mood improvement was assessed. It was expected that emotional eaters would consume more food than nonemotional eaters in the emotional conditions, and also more than in the neutral condition. Moderated regression analyses indeed showed a significant increase in food intake for emotional eaters in the positive compared to the neutral condition, and a trend towards higher food consumption than non-emotional eaters. No effects were found in the negative condition. With regard to mood changes during food intake, Pearson correlations demonstrated an association between amount of calories consumed and mood improvement after $5 \mathrm{~min}$ of food consumption. However, there was no evidence for differences between emotional and non-emotional eaters. The current findings underline the importance of positive emotions in emotional eating, and provide new insights on the relationship between eating and mood melioration. (c) 2013 Elsevier Ltd. All rights reserved.
\end{abstract}

\section{Introduction}

Emotional eaters report to overeat in response to negative emotions, and are therefore considered to be at risk for becoming overweight or even obese (Hays \& Roberts, 2008). The concept of emotional eating originated several decades ago already (Bruch, 1964; Kaplan \& Kaplan, 1957; Schachter, Goldman, \& Gordon, 1968), and questionnaires developed to measure emotional eating (e.g. Dutch Eating Behaviour Questionnaire (DEBQ) (Van Strien, 2005; Van Strien, Frijters, Bergers, \& Defares, 1986); Emotional Eating Scale (EES) (Arnow, Kenardy, \& Agras, 1995); Emotional Overeating Questionnaire (EOQ) (Masheb \& Grilo, 2006)) have been around for the past 25 years as well. However, until quite recently, researchers rarely distinguished their participants on being classified as emotional or non-emotional eaters (that is, emotional eaters are thought to increase their food intake in response to negative emotions, while non-emotional eaters will not change their consumption levels, or might even restrict intake), even though it is important to gain knowledge on how exactly emotions influence self-reported emotional eaters.

With regard to negative emotions, Oliver, Wardle, and Gibson (2000) manipulated stress levels in their participants and pre-

\footnotetext{
Acknowledgements: This study is part of an ongoing Project that is financed by the Netherlands Organisation for Scientific Research (NWO): Vici Grant 453.10.006, awarded to Anita Jansen.

* Corresponding author.

E-mail address: peggy.bongers@maastrichtuniversity.nl (P. Bongers).
}

sented them with sweet, salty and bland food, either high or low in caloric content. They found that emotional eaters in the stress condition consumed more sweet high-caloric foods than non-emotional eaters and participants in a non-stress condition. However, stress did not change overall food consumption. Evers, de Ridder, and Adriaanse (2009) showed in two experiments that participants scoring high on self-reported emotional eating did not consume more food after being brought in a negative emotional state than participants who scored low on emotional eating, nor did they increase their food intake in the emotional compared to the neutral condition. Adriaanse, de Ridder, and Evers (2011) found no influence of self-reported negative emotional eating on snacking in a diary-study.

In contrast to the previously described studies in which a negative mood was manipulated, Turner, Luszczynska, Warner, and Schwarzer (2010) induced a positive mood in emotional and non-emotional eaters, controlling for uncontrolled eating styles (i.e., difficulties with refraining from eating when food cues are presented). They found that food intake was not directly affected by emotional eating status. Finally, two studies induced both positive and negative moods in their participants. Kenardy, Butler, Carter, and Moor (2003) did not find any evidence for emotional eating after positive or negative mood induction, but did find lower food consumption in a negative compared to a positive mood, regardless of emotional eater status. Likewise, Evers et al. (2009) discovered no effects of either positive or negative emotions on food intake: emotional eaters did not consume more food than nonemotional eaters after any of the mood manipulations, nor did they 
have higher food intake after the emotional conditions compared to a neutral control condition.

Only this last study (Evers et al., 2009) manipulated both positive and negative mood, and included a control condition. Mood was manipulated by providing negative or positive feedback on the participant's performance on a task, thus being very personal and, in the negative condition, ego-threatening. Interestingly, studies in restrained eaters and dieters have shown that these specific groups of people actually tend to overeat when being in an egothreatening situation, even more so than in other negative situations, like watching frightening movies (Heatherton, Herman, \& Polivy, 1991; Lattimore, 2001; Wallis \& Hetherington, 2004). However, it appears from the previously discussed studies (Evers et al., 2009; Kenardy et al., 2003; Oliver et al., 2000) that this was not the case in emotional eaters. Therefore, in the current study, a nonthreatening mood manipulation was applied. Another reason for some of the null-findings in previous studies could be that participants were offered only salted crackers (i.e. Kenardy et al. (2003)), while some studies suggests that sweet high-fat foods are the preferred choice for emotional eaters (Konttinen, Männistö, SarlioLähteenkorva, Silventoinen, \& Haukkala, 2010; Oliver et al., 2000).

Another issue concerns why people overeat in response to emotions. In (sub) clinical populations, such as binge eaters, affect regulation theories have been proposed to explain excessive food intake in response to emotions. These theories state that people overeat to reduce the affect they are experiencing, especially when negative (Ganley, 1989; Heatherton \& Baumeister, 1991). It is quite imaginable that comparable processes might be working in emotional eaters. Macht and Mueller (2007) examined the effects of chocolate consumption after experimentally inducing negative mood, and found that mood became significantly more positive in emotional eaters compared to non-emotional eaters, although the latter group also experienced a mood improvement. After both negative and positive emotion inductions, participants in a study by Kenardy et al. (2003) decreased in negative affect after eating. However, no differences were found between emotional and non-emotional eaters. Although increased mood after eating has been established by these studies, it is still unknown whether the amount of food consumed is of importance in reaching this improvement.

The present research aimed to investigate a reciprocal model of mood change and food intake in emotional eaters, in which mood change leads to increased food intake, and food intake in turn leads to positive changes in mood. We studied the effect of negative and positive emotional states on caloric food intake in self-reported emotional eaters by employing a non-ego-threatening mood manipulation. Positive emotions were included to incorporate suggestions from the clinical field that people report overeating after positive emotions, as well as to replicate previous studies (e.g. Evers et al., 2009; Kenardy et al., 2003). We hypothesised that after both negative and positive emotions, emotional eaters would consume more calories than non-emotional eaters, and that their caloric intake would be higher in both emotional conditions compared to the control condition. A second aim of the study was to shed more light on the relationship between food intake and mood change in emotional and non-emotional eaters. We hypothesised that there is a positive association between caloric intake and mood, most pronounced in emotional eaters.

\section{Method}

\section{Participants}

Eighty-seven (65 female) psychology students, enrolled in their second year at Maastricht University, participated in this study in return for course credit. One participant was excluded due to giv- ing only extreme and inconsistent answers on several questionnaires. Age varied between 19 and 43 years $(M=21.6, \mathrm{SD}=2.8)$. The study was approved by the Maastricht University Ethical Committee.

\section{Measures}

\section{Positive and Negative Affect Schedule (PANAS)}

The PANAS (Watson, Clark, \& Tellegen, 1988; Dutch translation by Peeters, Ponds, \& Vermeeren, 1996) is a scale designed to measure the experience of several positive and negative affects during the past 2 weeks, such as: 'interested', 'determined', 'guilty' or 'distressed'. Ratings are made on a 5-point Likert-scale, ranging from 'very slight or not at all' to 'extremely'. Higher scores indicate more positive and/or negative affect. The PANAS has high reliability and internal consistency (Crawford \& Henry, 2004; Watson et al., 1988).

\section{Beck Depression Inventory-II (BDI-II)}

The BDI-II (Beck, Steer, \& Brown, 1996; Dutch translation by Van der Does (2002)) is a self-report questionnaire consisting of 21 items. All items have four statements each, and the participants have to select the answer that best describes their feelings and behaviours in the last 2 weeks. For example, with regard to crying, the four statements are as follows: 'I don't cry more than I used to', 'I cry more than I used to', 'I cry about every little thing', and 'I would like to cry, but I can't'. Total scores range from 0 to 63 , with scores between 0 and 13 indicating no depression, scores between 14 and 19 mild depression, between 20 and 28 moderate depression, and higher than 28 severe depression. Whisman, Perez, and Ramel (2000) found good internal consistency and reliability for the BDI-II.

\section{Dutch Eating Behaviour Questionnaire (DEBQ)}

The DEBQ (Van Strien, 2005; Van Strien et al., 1986) is a 33-item questionnaire designed to measure self-reported emotional eating, external eating and dietary restraint. All items are scored on a 5point Likert scale ranging from 'Never' to 'Very often'. Examples of items are 'Do you have a desire to eat when you are feeling lonely?' (Emotional eating), 'If food smells and looks good, do you eat more than usual?' (External eating), and 'How often do you try not to eat in between meals because you are watching your weight?' (Dietary restraint). Means are calculated for the three subscales and higher scores (within a range from 1 to 5 ) indicate increased emotional, external or restrained eating.

\section{Mood induction}

Positive and negative mood were induced by means of movie excerpts. The use of film clips has proven to be a successful method in changing subjective states (Chua, Touyz, \& Hill, 2004; Cools, Schotte, \& McNally, 1992; Evers et al., 2009; Sheppard-Sawyer, McNally, \& Fischer, 2000; Turner et al., 2010; Yeomans \& Coughlan, 2009). In the current study, the positive movie fragment consisted of two combined scenes. The first scene was taken from the tv-series 'Mr. Bean' (1990), and shows Mr. Bean struggling to copy answers from his neighbor while taking an exam. The second scene was taken from the movie 'When Harry met Sally' (1989), and depicts a male and female friend enjoying dinner, when at one point the female simulates an orgasm in front of the full restaurant. The negative fragment came from the movie 'The Green Mile' (1999), showing an innocent man undergoing his death sentence. For the neutral control condition, part of a documentary on fishing was shown. Participants were randomly assigned to one of the three conditions. 


\section{Manipulation check}

Subjective mood states were measured using $100 \mathrm{~mm}$ Visual Analogue Scales (VAS). Seven VASs were administered at five time points during the experiment. The scales asked for how frightened, sad, happy, guilty, enthusiastic, nervous and ashamed one felt at the moment, and ranged from 'not at all' $(0)$ to 'very much' (100). Higher scores indicated a higher experience of that particular emotion.

\section{Food intake}

An alleged taste test was set up to measure caloric food intake in participants. The foods presented were salty crisps $(5.45 \mathrm{kcal} / \mathrm{g})$, ketchup crisps (5.40 kcal/g) and mixed white, milk and dark chocolate $(5.25 \mathrm{kcal} / \mathrm{g})$, all in large glass bowls. To cater for differences in food preferences and to ensure food variety, our participants were presented with both sweet and savoury high-fat food items. Studies have shown that increased food variety diminishes sensory specific satiety (Brondel et al., 2009; Norton, Anderson, \& Hetherington, 2006). Bowls contained an average of $190.64 \mathrm{~g}$ (1000 kcal) of chocolate, $225.46 \mathrm{~g}$ (1229 kcal) of salted crisps, and $225.44 \mathrm{~g}$ ( $1217 \mathrm{kcal})$ of ketchup crisps. They were weighed in a separate room before and after tasting and amount of calories eaten were calculated. We were interested in total caloric intake, and the means and standard deviations of kilocalories presented and consumed during the taste test are presented in Table 1 . There were no differences between conditions in amount of kilocalories presented during the taste test, $F(2,83)=0.22, p=.81$. To ensure the cover story of a taste test was convincing, a 24-item questionnaire was constructed, with items pertaining to the taste, structure and appearance of the food. Participants were told that they had $15 \mathrm{~min}$ to complete this paper and pencil questionnaire, and that they could eat as much of the food as they liked.

\section{Awareness check}

Participants were asked to describe what they thought the current study was about. The answer to this question gives an indication of whether participants might be aware of the true purpose of the research.

\section{Procedure}

Upon entering the lab, participants were seated behind a computer and were told they were about to take part in an experiment investigating the influence of movie clips on taste perception. The procedure started with filling out the first series of VAS mood scales, followed by watching either a positive, negative or neutral film fragment. Participants were instructed to give into the feelings the movie fragment evoked in them. When the fragment was finished, participants filled out the VAS scales for the second time. The experimenter then left the room and came back with three bowls of food containing ketchup crisps, salty crisps and small chocolates for the taste test. A glass of water was also provided. In addition, they were provided with two more VAS scales assessing mood, and it was explained to them that they would hear a tone twice during the tasting (after 5 and $10 \mathrm{~min}$ ), which indicated filling out a VAS scale. The experimenter then left the room to return 15 min later, administering the fifth and final mood measure- ment. After the taste test, participants filled out the BDI, PANAS, DEBQ and manipulation checklist, and height and weight were measured. To counteract possible long-lasting negative effects of watching the negative movie clip, participants in this condition were shown the positive fragment when they had completely finished the experiment.

\section{Data analysis}

One-way ANOVA's were used to check for pre-existing differences between conditions on age, BMI, depression, positive and negative affect, emotional and external eating, dietary restraint, and current mood. A 2 (time: before vs. after) $\times 3$ (condition: negative vs. neutral vs. positive) MANOVA followed by simple effects analysis was performed to determine the success of the mood manipulation. For the main analysis, a hierarchical regression analysis was conducted. Gender, BMI, DEBQ external eating, DEBQ dietary restraint, and Negative Affect were taken into consideration as possible confounders. To avoid problems with multicollinearity, all variables were centered prior to entering the interaction term in the model. The variance inflation factor (VIF) and tolerance statistics indicated no evidence for multicollinearity, with VIFs close to 1 and tolerance never below 0.2. The Durbin-Watson statistic remained close to 2 , thereby confirming that the assumption of independent errors was not violated. In addition, dummy variables were created for the three conditions (with the neutral condition acting as the reference group). To test the second hypothesis, bivariate and partial Pearson correlations were conducted. Three participants had incomplete $(N=1)$ or outlying $(N=2)$ data regarding mood measurements, and were not included in the correlations.

\section{Results}

\section{Participant characteristics}

A one-way ANOVA showed no pre-existing differences between participants in the positive ( 17 female, 11 male), negative ( $24 \mathrm{fe}-$ male, 4 male) and neutral conditions ( 23 female, 7 male), as shown in Table 2. A chi-square test indicated equal gender distribution over conditions, $X^{2}(2, N=86)=4.72, p=.094$.

\section{Mood manipulation}

Negative VAS ratings were reverse scored, added to the positive ratings and divided by two. This resulted in one single mood score for each time-point, with higher scores indicating a more positive mood. A 2 (time: before vs. after mood induction) $\times 3$ (condition: negative vs. neutral vs. positive) MANOVA on subjective mood ratings before and after viewing the movie fragments was conducted, with the first factor within subjects and the second factor between subjects. The analysis revealed a significant multivariate interaction effect, $F(2,83)=25.16, p<.001$. Subsequent simple main effects showed no significant differences in mood between conditions at baseline, $F(2,83)=2.39, p=.09$. Mood induction was successful in the positive condition, with participants becoming more positive (pre, $M=73.89, \mathrm{SD}=6.88$; post, $M=79.50$,

Table 1

Means and standard deviations of food presentation and food consumption in kilocalories per condition.

\begin{tabular}{|c|c|c|c|c|c|c|}
\hline & \multicolumn{2}{|c|}{ Negative condition $(N=28)$} & \multicolumn{2}{|c|}{ Neutral condition $(N=30)$} & \multicolumn{2}{|c|}{ Positive condition $(N=28)$} \\
\hline & $M$ & SD & $M$ & SD & $M$ & SD \\
\hline Food presentation & 3447.94 & 10.87 & 3446.01 & 13.52 & 3447.00 & 8.40 \\
\hline Food consumption & 191.58 & 120.53 & 172.22 & 125.94 & 202.31 & 157.97 \\
\hline
\end{tabular}


Table 2

Means and standard deviations of participant characteristics per condition.

\begin{tabular}{|c|c|c|c|c|c|c|c|c|}
\hline & \multicolumn{2}{|c|}{ Negative condition $(N=28)$} & \multicolumn{2}{|c|}{ Neutral condition $(N=30)$} & \multicolumn{2}{|c|}{ Positive condition $(N=28)$} & \multirow[t]{2}{*}{$F$} & \multirow[t]{2}{*}{$p$} \\
\hline & $M$ & SD & $M$ & SD & $M$ & SD & & \\
\hline Age & 21.54 & 1.58 & 21.23 & 1.50 & 21.14 & 1.60 & .49 & .62 \\
\hline BMI & 23.89 & 4.97 & 23.66 & 3.77 & 23.10 & 3.08 & .28 & .75 \\
\hline BDI & 5.75 & 4.43 & 5.13 & 4.40 & 5.71 & 3.94 & .19 & .83 \\
\hline Positive affect $^{\mathrm{a}}$ & 32.04 & 5.88 & 30.93 & 6.23 & 32.14 & 5.39 & .38 & .68 \\
\hline Negative affect ${ }^{\mathrm{a}}$ & 17.86 & 6.09 & 18.43 & 5.90 & 18.79 & 6.80 & .16 & .86 \\
\hline Emotional eating & 2.38 & 0.79 & 2.18 & 0.76 & 2.13 & 0.64 & .93 & .40 \\
\hline External eating ${ }^{\mathrm{b}}$ & 3.22 & 0.59 & 3.19 & 0.48 & 3.35 & 0.60 & .61 & .55 \\
\hline Dietary restraint ${ }^{\mathrm{b}}$ & 2.20 & 0.86 & 2.52 & 0.76 & 2.59 & 0.89 & 1.72 & .19 \\
\hline Current mood ${ }^{\mathrm{c}}$ & 75.39 & 9.17 & 69.92 & 12.55 & 73.89 & 6.88 & 2.39 & .10 \\
\hline
\end{tabular}

a Positive and negative affect measured by PANAS.

b Emotional eating, external eating, and dietary restraint measured by DEBQ.

c Mood measured by $100 \mathrm{~mm}$ VAS scales at baseline, higher scores indicate better mood.

$\mathrm{SD}=10.84, F(1,83)=9.66, p=.003)$ after watching the movie clip. In the negative condition participants were significantly more negative after the manipulation (pre, $M=75.39, \mathrm{SD}=9.17$; post, $M=63.24, \mathrm{SD}=12.98, F(1,83)=45.26, p<.001)$. In the neutral condition, participant's mood did not change (pre, $M=69.92$, $\mathrm{SD}=12.55$; post, $M=69.66, \mathrm{SD}=11.49, F(1,83)=.02, p=.89)$. It was concluded that the mood manipulations were successful.

Hypothesis 1: After both negative and positive emotions, emotional eaters will consume more calories than non-emotional eaters. In addition, their caloric intake will be higher in both emotional conditions compared to the control condition.

Participants in the three conditions did not differ in caloric intake, $F(2,83)=0.37, p=.69$, as shown in Table 1 . In order to test the hypothesis, a hierarchical multiple regression was performed. Gender, BMI, DEBQ External Eating scores, DEBQ Dietary Restraint scores, and negative affect were entered in the first block as control variables. In the second block, condition and emotional eating scores were entered, and finally the Condition $\times$ Emotional Eating interaction terms were added in the third block. The results of the regression analysis are shown in Table 3. With regard to the control variables, only the DEBQ external eating score was a significant predictor, $\beta=.25, t(85)=2.12, p=.04$. The variables added in block 2 (condition and emotional eating scores) did not change the model significantly, $\Delta R^{2}=.005, p=.93$, but the third block revealed a significant effect of the interaction between condition (neutral vs. positive) and emotional eating scores on food intake $\Delta R^{2}=.07$, $p=.04$.
Simple slopes and interactions with standardised regression coefficients for participants scoring high ( +1 SD; emotional eaters) and low ( $-1 \mathrm{SD}$; non-emotional eaters) on emotional eating are plotted in Fig. 1. When comparing the emotional and non-emotional eaters, there was a trend-significant difference in the positive condition, in which emotional eaters tended to eat more than non-emotional eaters, $\beta=.42, t(85)=1.87, p=.07$. In the neutral condition there was a trend-significant difference in the opposite direction, $\beta=-.30, t(85)=1.72, p=.09$, whereas there were no differences between emotional and non-emotional eaters in the negative condition, $\beta=.06, t(85)=0.34, p=.74$ Looking within the group of emotional eaters, there was significantly higher food intake in the positive compared to the neutral condition, $\beta=-.46$, $t(85)=2.43, p=.02$, and no difference between the negative and neutral conditions, $\beta=-.20, t(85)=1.24, p=.22$ or negative and positive conditions, $\beta=-.26, t(85)=1.44, p=.16$. There were no differences between conditions in the non-emotional eaters, all $t$ 's $<-1.31$, all $p$ 's $>.19$. In sum, emotional eaters ate more in a positive than in a neutral mood whereas there were no differences for non-emotional eaters. Negative mood had no effect on food consumption in both types of eaters (emotional and non-emotional).

Hypothesis 2: In self-reported emotional eaters, there will be a positive association between caloric intake and mood.

Mood difference scores were calculated by subtracting mood immediately following viewing of the film clip from mood after 5,10 , and 15 min of tasting. Table 4 shows the mean mood scores on the four time points and before the film for the group as a whole, as well as separated for emotional and non-emotional eaters. A 2 (emotional vs. non-emotional eater) $\times 5(\operatorname{mood}$ at the 5

Table 3

Results of hierarchical regression analysis $(N=86)$.

\begin{tabular}{|c|c|c|c|c|c|c|}
\hline \multirow[t]{3}{*}{ Variables and steps ${ }^{\dagger}$} & \multicolumn{6}{|c|}{ Caloric intake } \\
\hline & \multicolumn{2}{|l|}{ Step 1} & \multicolumn{2}{|l|}{ Step 2} & \multicolumn{2}{|l|}{ Step 3} \\
\hline & B & SE & B & SE & B & SE \\
\hline Gender & 25.14 & 37.27 & 27.00 & 38.46 & 15.71 & 37.70 \\
\hline BMI & -6.05 & 3.58 & -5.91 & 3.66 & -4.29 & 3.63 \\
\hline External eating & $59.82^{*}$ & 28.22 & 57.37 & 31.62 & 45.74 & 31.23 \\
\hline Dietary restraint & -20.98 & 20.68 & -21.87 & 21.97 & -29.71 & 21.52 \\
\hline Negative affect & -1.54 & 2.48 & -1.47 & 2.52 & -1.08 & 2.46 \\
\hline Emotional eating & & & .076 & 22.58 & -55.61 & 32.39 \\
\hline Condition (neutral vs. negative) & & & 7.01 & 35.52 & 7.28 & 34.66 \\
\hline Condition (neutral vs. positive) & & & 22.58 & 34.95 & 34.69 & 34.23 \\
\hline Emotional eating $\times$ neutral-negative & & & & & 67.10 & 44.54 \\
\hline Emotional eating $\times$ neutral-positive & & & & & $132.03^{*}$ & 51.10 \\
\hline$R^{2}$ & \multicolumn{2}{|c|}{.142} & \multicolumn{2}{|c|}{.147} & \multicolumn{2}{|c|}{.218} \\
\hline$\Delta R^{2}$ & \multicolumn{2}{|c|}{$.142^{*}$} & \multicolumn{2}{|c|}{.005} & \multicolumn{2}{|c|}{$.071^{*}$} \\
\hline
\end{tabular}

Note: $B$ is the unstandardized regression coefficient.

$p<.05$. 


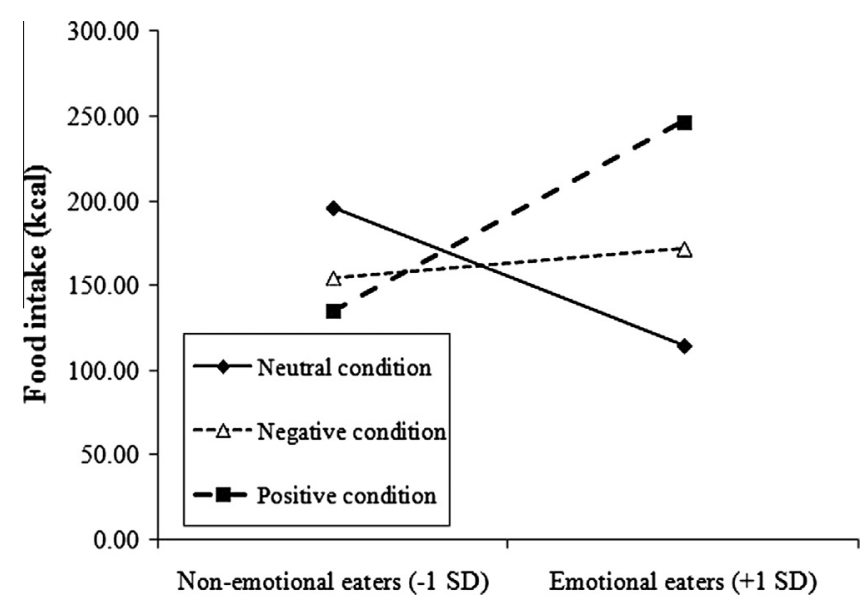

Fig. 1. Food intake as a function of condition and emotional eating scores ( $-1 \mathrm{SD}$ and +1 SD from the mean DEBQ score, respectively).

time-points) mixed ANOVA with Greenhouse-Geisser correction showed a main effect of mood, $F(2.30,191.21)=12.65, p=.00$. There was no significant interaction between mood and emotional eater type, $F(2.30,191.21)=1.84, p=.16$, nor was there was a significant effect of eater type, indicating that mood improvement for emotional and non-emotional eaters was the same, $F(1,83)=.24, p=.62$. Simple contrasts revealed that mood at each time-point during the taste test was significantly better than mood immediately after the film all $F \mathrm{~s}(1,83)>16.51$, all $p$ 's $<.001$. In other words, mood increased significantly in the first 5 min of eating, and remained constant thereafter.

Due to the sample size and the fact that we do not expect differences between conditions in the mood effect of calorie intake, correlations over all conditions taken together are reported. Bivariate Pearson correlation coefficients for the group as a whole indicated an association between caloric intake and mood improvement after 5 min of eating. Follow-up partial Pearson correlations with DEBQ emotional eating scores as covariate led to similar results $(p=.052)$. The results of the partial correlations indicate that emotional eating scores are not relevant to the association between caloric intake and mood improvement. All correlations are shown in Table 5.

\section{Discussion}

This study showed that self-reported emotional eaters respond in a different way to emotions than non-emotional eaters. Emotional eaters ate more in a positive mood compared to a neutral mood whereas non-emotional eaters ate about the same amount in both conditions. Within the positive mood condition, emotional eaters also tended to eat more than non-emotional eaters. Contrary to expectations, a negative mood did not increase the calorie consumption of emotional eaters. A significant positive correlation between calorie intake and mood improvement was found: the more calories participants ate in the first 5 min of tasting, the better their mood. However, being an emotional or non-emotional eater did not influence this association.
Table 5

Pearson correlations between calorie intake, emotional eating, and mood improvement.

\begin{tabular}{llll}
\hline & \multicolumn{3}{l}{ Minutes into taste test } \\
\cline { 2 - 4 } & 5 & 10 & 15 \\
\hline Bivariate correlations $(N=83)$ & $.22^{* *}$ & .07 & .10 \\
Partial correlations $(N=83)^{\mathrm{a}}$ & $.22^{*}$ & .06 & .09 \\
\hline
\end{tabular}

a DEBQ emotional eating scores were added as a covariate in the partial correlations.

** $p<.05$.

${ }^{*} p=.052$.

Our findings are in line with some previous studies, showing higher food intake after positive compared to negative emotions in non-depressed binge eaters (Dingemans, Martijn, van Furth, \& Jansen, 2009), a non-clinical sample of students (Kenardy et al., 2003), and underweight people (Geliebter \& Aversa, 2003). Other researchers found that obese people (Patel \& Schlundt, 2001), restrained eaters (Cools et al., 1992), and people characterised by uncontrolled eating styles (Turner et al., 2010) consumed more in a positive than in a neutral mood. In short, these studies all point to increased food intake during positive emotions for eating- or weight concerned people (e.g. emotional and restrained eaters, as well as obese and underweight people). In a clinical or real-world setting, positive moods might be underestimated as a risk factor for overeating. However, mechanisms explaining why a positive mood would lead to overeating in these groups have not yet been identified.

Most self-reported emotional eating is related to negative moods and even the questionnaire we used to select emotional eaters, that is, the DEBQ only asks for self-reported eating in response to negative moods. However, the high scorers on this questionnaire did not overeat in response to negative emotions whereas they did overeat in response to positive emotions. Why did emotional eaters not overeat in a negative mood?

One explanation is that the laboratory setting could have made participants feel observed and uncomfortable, which prevented them from overeating. Another possibility is that a standard mood manipulation like we used may not be able to trigger the right mood for overeating in every participant. A mood manipulation tailored to the individual might lead to more convincing results. However, naturalistic diary studies (Adriaanse et al., 2011; Conner, Fitter, \& Fletcher, 1999) were also unable to find effects of emotional eating scores on food intake after negative events. In addition, we did find overeating in the positive mood condition, in the same laboratory setting and also using a standardised mood induction. Kenardy et al. (2003) argued that emotional overeating may only be present in clinical samples. A further explanation could be that real emotional eaters do overeat in a negative mood, but that the questionnaire used in this study (DEBQ) was not sensitive or valid enough to truthfully measure emotional eating and identify emotional eaters. Indeed, some controversy has arisen on the validity of emotional eating scales. While it was empirically shown that emotional eating may occur, there is less consensus about emotional eating scales being the most fruitful way to identify emotional eaters. Evers et al. (2009) questioned the validity of

Table 4

Means and standard deviations of mood scores before and during taste test.

\begin{tabular}{|c|c|c|c|c|c|c|c|c|c|c|}
\hline & \multirow{2}{*}{\multicolumn{2}{|c|}{ Before film }} & \multirow{2}{*}{\multicolumn{2}{|c|}{ After film }} & \multicolumn{6}{|c|}{ Minutes into taste test } \\
\hline & & & & & \multicolumn{2}{|l|}{5} & \multicolumn{2}{|l|}{10} & \multicolumn{2}{|l|}{15} \\
\hline & M & SD & M & SD & M & SD & M & SD & $\mathrm{M}$ & SD \\
\hline Total sample $(N=83)$ & 72.84 & 10.13 & 71.17 & 12.58 & 75.51 & 10.50 & 74.80 & 11.00 & 75.35 & 11.55 \\
\hline Non-emotional eaters $(N=46)$ & 72.50 & 10.28 & 72.54 & 12.12 & 76.00 & 10.87 & 75.12 & 11.08 & 75.71 & 11.53 \\
\hline Emotional eaters $(N=37)$ & 73.26 & 10.07 & 69.47 & 13.09 & 74.91 & 10.14 & 74.40 & 11.03 & 74.90 & 11.71 \\
\hline
\end{tabular}


emotional eating scales, stressing the difficulties and biases people encounter when recalling/judging their own behaviour. Agras and Telch (1998) suggested that a negative mood decreases the sense of control a binge eater has over eating, thereby estimating intake to be higher than it actually is. If this is applicable to self-reported emotional eaters or the population in general as well, people might easily overestimate their intake in negative moods and are therefore not able to fill out emotional eating questionnaires in an objective way. Adriaanse et al. (2011) proposed that it is the "concerned eaters' (e.g., those who worry about and monitor their eating behaviour) who tend to score high on measures of emotional eating, while in fact not being emotional eaters at all. A similar suggestion of 'concerned eaters' was made by Jansen et al. (2011), who found no discriminant validity between emotional, external and restraint eating scales.

The second aim of this study was to investigate the influence of food intake on mood. Emotional eating is supposed to exist because the act of consuming food is assumed to improve mood. We expected a mood improvement that is highly correlated with calorie intake in self-reported emotional eaters. Pearson correlations did confirm the hypothesis that mood improved by eating calories, but only in the first $5 \mathrm{~min}$ of the taste test, and for the whole sample, i.e. not only for emotional eaters. With regard to mood improvement after food consumption, our findings fit with the studies showing mood improvement after eating (Agras \& Telch, 1998; Dingemans, Martijn, Jansen, \& van Furth, 2009; Kenardy et al., 2003; Macht \& Mueller, 2007). In addition we showed that the amount of calories eaten is significantly correlated to the amount of mood improvement in the first $5 \mathrm{~min}$ of eating. Whereas Macht and Mueller (2007) reported stronger effects for emotional eaters, we did not find any differences between the two types of eaters: mood improved after eating, in both the emotional and non-emotional eaters.

One important limitation to mention with regard to the second hypothesis is that there was no non-eating control group. Therefore it is impossible to conclude that the changes in mood were actually due to food intake, and not to other factors, such as simply the passing of time.

Another limitation of the study is that there were no hunger measurements taken. Hunger levels could influence food intake beyond the effects of mood, possibly confounding the results. However, since participants were randomised over conditions, this should not have caused differences between groups. Furthermore, one could argue that measuring eating behaviour in a lab environment is disadvantageous as well. Lab environments may prevent people (especially those who have issues concerning eating, such as emotional eaters) from eating as much as they would normally do. However, considering that increased food intake was found in emotional eaters in the positive condition, this concern is largely irrelevant. Finally, to avoid priming effects, the DEBQ was administered at the end of the experiment, after the mood manipulation and bogus taste test. However, we cannot exclude the possibility that the manipulation influenced scores on the questionnaire.

The present findings, although in need of replication, could be of value for the treatment of obesity. Considering that emotional eating is a risk factor for becoming obese (Hays \& Roberts, 2008), gaining a deeper understanding of the processes involved in emotional eating are of importance in combating the obesity epidemic. The current study underlines the importance of positive emotions in overeating, which are often overlooked.

\section{References}

Adriaanse, M. A., de Ridder, D. T. D., \& Evers, C. (2011). Emotional eating. Eating when emotional or emotional about eating? Psychology \&' Health, 26(1), 23-39.
Agras, W. S., \& Telch, C. F. (1998). The effects of caloric deprivation and negative affect on binge eating in obese binge-eating disordered women. Behavior Therapy, 29(3), 491-503.

Arnow, B., Kenardy, J., \& Agras, W. S. (1995). The emotional eating scale. The development of a measure to assess coping with negative affect by eating. International Journal of Eating Disorders, 18(1), 79-90.

Beck, A., Steer, R., \& Brown, G. (1996). Manual for the beck depression inventory-II. San Antonio, TX: Psychological Corporation.

Brondel, L., Romer, M., van Wymelbeke, V., Pineau, N., Jiang, C., Hanus, C., et al. (2009). Variety enhances food intake in humans. Role of sensory-specific satiety. Physiology \& Behavior, 97, 44-51.

Bruch, H. (1964). Psychological aspects of overeating and obesity. Psychosomatics, 5(5), 269.

Chua, J. L., Touyz, S., \& Hill, A. J. (2004). Negative mood-induced overeating in obese binge eaters. An experimental study. International Journal of Obesity, 28(4), 606-610.

Conner, M., Fitter, M., \& Fletcher, W. (1999). Stress and snacking. A diary study of daily hassles and between-meal snacking. Psychology \& Health, 14(1), 51-63.

Cools, J., Schotte, D. E., \& McNally, R. J. (1992). Emotional arousal and overeating in restrained eaters. Journal of Abnormal Psychology, 101(2), 348-351.

Crawford, J. R., \& Henry, J. D. (2004). The Positive and Negative Affect Schedule (PANAS). Construct validity, measurement properties and normative data in a large non-clinical sample. British Journal of Clinical Psychology, 43(3), 245-265.

Dingemans, A. E., Martijn, C., Jansen, A., \& van Furth, E. F. (2009). The effect of suppressing negative emotions on eating behavior in binge eating disorder. Appetite, 52(1), 51-57.

Dingemans, A. E., Martijn, C., van Furth, E. F., \& Jansen, A. (2009). Expectations, mood, and eating behavior in binge eating disorder. Beware of the bright side. Appetite, 53(2), 166-173.

Evers, C., de Ridder, D. T. D., \& Adriaanse, M. A. (2009). Assessing yourself as an emotional eater. Mission impossible? Health Psychology, 28(6), 717-725.

Ganley, R. M. (1989). Emotion and eating in obesity. A review of the literature. International Journal of Eating Disorders, 8(3), 343-361.

Geliebter, A., \& Aversa, A. (2003). Emotional eating in overweight, normal weight, and underweight individuals. Eating Behaviors, 3(4), 341-347.

Hays, N. P., \& Roberts, S. B. (2008). Aspects of eating behaviors 'disinhibition' and 'restraint' are related to weight gain and BMI in women. Obesity, 16(1), 52-58.

Heatherton, T., \& Baumeister, R. (1991). Binge eating as escape from self-awareness. Psychological Bulletin, 110(1), 86-108.

Heatherton, T., Herman, C., \& Polivy, J. (1991). Effects of physical threat and ego threat on eating behavior. Journal of Personality and Social Psychology, 60(1), 138

Jansen, A., Nederkoorn, C., Roefs, A., Bongers, P., Teugels, T., \& Havermans, R. (2011). The proof of the pudding is in the eating. Is the DEBQ. External eating scale a valid measure of external eating? International Journal of Eating Disorders, 44(2), 164-168.

Kaplan, H. I., \& Kaplan, H. S. (1957). The psychosomatic concept of obesity. Journal of Nervous and Mental Disease, 125, 181-201.

Kenardy, J., Butler, A., Carter, C., \& Moor, S. (2003). Eating, mood, and gender in a noneating disorder population. Eating Behaviors, 4(2), 149-158.

Konttinen, H., Männistö, S., Sarlio-Lähteenkorva, S., Silventoinen, K., \& Haukkala, A (2010). Emotional eating, depressive symptoms and self-reported food consumption. A population-based study. Appetite, 54(3), 473-479.

Lattimore, P. (2001). Stress-induced eating. An alternative method for inducing egothreatening stress. Appetite, 36(2), 187-188.

Macht, M., \& Mueller, J. (2007). Immediate effects of chocolate on experimentally induced mood states. Appetite, 49(3), 667-674.

Masheb, R. M., \& Grilo, C. M. (2006). Emotional overeating and its associations with eating disorder psychopathology among overweight patients with binge eating disorder. International Journal of Eating Disorders, 39(2), 141-146.

Norton, G. N. M., Anderson, A. S., \& Hetherington, M. M. (2006). Volume and variety. Relative effects on food intake. Physiology \& Behavior, 87, 714-722.

Oliver, G., Wardle, J., \& Gibson, L. (2000). Stress and food choice. A laboratory study. Psychosomatic Medicine, 62(6), 853-865.

Patel, K. A., \& Schlundt, D. G. (2001). Impact of moods and social context on eating behavior. Appetite, 36(2), 111-118.

Peeters, F. P. M. L., Ponds, R. W. H. M., \& Vermeeren, M. T. G. (1996). Affectiviteit en zelfbeoordeling van depressie en angst [Affectivity and self-report of depression and anxiety]. Tijdschrift voor Psychiatrie, 38, 240-250.

Schachter, S., Goldman, R., \& Gordon, A. (1968). Effects of fear, food deprivation, and obesity on eating. Journal of Personality and Social Psychology, 10(2), 91-97.

Sheppard-Sawyer, C. L., McNally, R. J., \& Fischer, J. H. (2000). Film-induced sadness as a trigger for disinhibited eating. International Journal of Eating Disorders, 28(2), 215-220.

Turner, S. A., Luszczynska, A., Warner, L., \& Schwarzer, R. (2010). Emotional and uncontrolled eating styles and chocolate chip cookie consumption. A controlled trial of the effects of positive mood enhancement. Appetite, 54(1), 143-149.

Van der Does, A. J. W. (2002). Handleiding bij de Nederlandse versie van Beck Depression. Inventory-second edition (BDI-II-NL) [Manual for the Dutch version of the Beck. Depression Inventory-second edition (BDI-II-NL)]. Harcourt Assessment, The Netherlands.

Van Strien, T. (2005). Nederlandse vragenlijst voor eetgedrag (NVE). Handleiding [Dutch Eating Behaviour Ouestionnaire Manual]. Boom Test Publishers.

Van Strien, T., Frijters, J. E., Bergers, G. P., \& Defares, P. B. (1986). The Dutch Eating Behavior Questionnaire (DEBQ) for assessment of restrained, emotional, and external eating behavior. International Journal of Eating Disorders, 5(2), 295-315. 
Wallis, D. J., \& Hetherington, M. M. (2004). Stress and eating. The effects of egothreat and cognitive demand on food intake in restrained and emotional eaters. Appetite, 43(1), 39-46.

Watson, D., Clark, L. A., \& Tellegen, A. (1988). Development and validation of brief measures of positive and negative affect. The PANAS scales. Journal of Personality and Social Psychology, 54(6), 1063-1070.
Whisman, M. A., Perez, J. E., \& Ramel, W. (2000). Factor structure of the beck depression inventory-second edition (BDI-II) in a student sample. Journal of Clinical Psychology.

Yeomans, M. R., \& Coughlan, E. (2009). Mood-induced eating. Interactive effects of restraint and tendency to overeat. Appetite, 52(2), 290-298. 